an occupational therapy training college, or a practising occupational therapist, so that the combined contributions form a first-hand picture of the living scene.

The book is divided into seven parts. Parts I and II offer three chapters by the Editors on evolution, techniques, and principles of treatment; Part III comprises six chapters on physical medicine with emphasis on rehabilitation and re-education, and where this is not possible, aids to daily living, to give the permanently disabled maximum independence. Part IV, in its five chapters, deals with the psychiatric field, where occupational therapy keeps step by step with other medical treatments, and in this field there is a plea for 'true therapy, medically prescribed, and expertly applied for the definite purpose of dealing with the specific medical problem of the individual'. Accounts of such treatment are illustrated by case histories.

Part V (two chapters) deals with occupational therapy for children with physical and psychological disorders, in both emphasis is laid on 'complete accord between those who undertake the treatment of a sick or handicapped child'. Part VI has four chapters on the treatment of cerebral palsies, children and adults, both in need of individual treatment; graded occupational therapy for the tuberculous; a 'therapeutic leam' for the treatment of geriatric cases, for whom a unified programme may save both conflict and confusion; and finally domiciliary occupational therapy, with the new powers to local authorities given by the 1946 and 1948 Health Services and Assistance Acts, to provide rehabilitation services to disabled persons in their own homes, and in treatment centres.

Part VII (three chapters) is concerned with administration, assessment-in which an occupational therapist can often be of help to the doctor-and social and industrial resettlement, giving information on methods of provision to the disabled and facilities available through statutory bodies and voluntary organizations.

The book is concluded by Appendices I-VII, giving detailed information on mechanics for occupational therapy; evaluation of activities; movement analysis; psychological evaluation and job analysis; a variety of referral forms; a full bibliography, and finally, useful information on correspondence courses and suppliers of self-aids.

No doubt much of the material in each section, representative as it can only be of one school of thought, will be provocative; but the book is a comprehensive one and as a reference book the clear division into parts, chapter headings and summaries concluding the chapters, with the exception of the references which might have been more conveniently placed as footnotes on the page, make for easy 'way finding' so that it could be easily 'dipped into' by those who are not able to give it full perusal.

\section{An Approach to Occupational Therapy}

\section{A survey based on the observation of 4,115 patients treated in Farnham Park Recuperative Home, October 1947-December 1955}

Mary S. Jones, M.C.S.P., M.A.o.T. Pp. xv +245 + index, illustrated. London: Butterworths. 1960. $42 s$.

This is a book about a very specialized branch of occupational therapy, but one about which we shall surely hear more in the future, as it bridges that often most uncomfortable and most demoralizing gap between discharge from hospital and return to normal occupation. It bridges it in such a way that, instead of boredom, bad movement habits and fear of permanent impairment which so often beset a patient left to make the final grade at home, the patients at a recuperative centre such as this book describes find companionship and interesting activities, while working at machines and occupations specifically designed and graded to give them the maximum recovery.

A man who scythes a field is a fit man; watch him today upon the mountains, very often an old man, the muscles of his head, trunk and limbs working in such perfect harmony and rhythm that many a younger man, perched tensely upon his bone-shaking machine in a 'more progressive country', might not be able to emulate him and one wonders if man is becoming the slave of the machine. One of the most refreshing things about Mrs. Jones's book is that she reverses this process and has invented and adapted machines, described in this book with ample clear working drawings and plates, to serve the purpose of restoring to natural working order the finest of all machines-the human body. The muscle work of the body appeals to Mrs. Jones's imagination as ' a form of ballet', a theme which runs through the book, from the two early chapters on 'Muscle Movement and Posture' and 'Occupational Therapy and Good Posture' emphasizing the need for the re-education of the postural reflexes by 'smooth, rhythmic movement' since 'to make tools do their work, co-ordination of movement, poise and control are more necessary than power'. To achieve this at Farnham Park, Mrs. Jones has accepted the traditional crafts of the area-woodwork and light metal work for the workshop and such outdoor activities as prove suitable to the recuperative programme.

In the long chapters which form the bulk of the book, on disabilities of the spine and lower and upper limbs, the author gives anatomical comments, tables of disabilities treated, recommendation for occupationa therapy and illustrative case histories. This pattern is kept throughout, and a notable feature of these chapter is the author's invention of 'lively splints' and tem porary prostheses aimed at giving purposeful activity with re-education and maintenance of muscle power during the period of waiting for permanent prostheses. Constructional diagrams and plates are given of all such aids with medical notes on advisability and precautions in their use. Finally, it is shown that the same workshop treatment can be effective for patients suffering from disorders of the abdomen, lungs and thorax, and generalized disabilities such as hemiplegia brain lesions, anterior poliomyelitis and heart conditions.

There are several features in this book which make it worthy of note by the medical profession. It makes an important contribution to the long-felt want of literature on occupational therapy, and, illustrated as it is throughout by clear working drawings, diagrams and photographs of the specialized machinery described, it makes one realize how highly specialized this branch of occupational therapy is, while its author entitles it merely ' an approach' to emphasize the belief that the field of study is vast and that we have much to learn. She feels that to supplement information obtained from a doctor's clinic, where nervousness on the part of many patients may give a distorted picture, an occupational therapist may have valuable information to give from 'observations made in workshops and gardens', where 'patients are in something approaching their natural surroundings ', and yet are engaged in occupations which have 'therapy' as their main purpose.

In this age of kaleidoscopic production, where machines may be out of date almost before they are on the market, this author's interest in the unchanging machine of the human body and the personalities that work it is characterized by elements of greatness, based upon her medical knowledge, her fascination of interest, 
sense of humour, and deep appreciation of ' the courage and often heroism with which many of the victims of injury and disease have met their misfortune' so that the reader closes the book affirming the verdict of its Foreword-'She has an enthralling tale to tell'.

\section{Good English for Medical Writers}

Ffrangcon Roberts, M.A., M.D., F.F.R. Pp. ix + 179. London: William Heinemann. 1960. I7s. $6 d$.

A book to help medical authors to write better English is badly needed, and it is surprising that so few books of this kind have been written. Presumably few people dare face the risks which Dr. Ffrangcon Roberts mentions at the end of his introduction (p. 6). ' I quite expect readers to point the finger of scorn at me when they discover, as they certainly will, that I have myself committed many of the sins that I condemn'.

This disarming admission makes it seem churlish to look too closely at the occasional blemishes, but it is disconcerting to find on the third page of a book which sets out to show you how to say exactly what you mean, a sentence which fails as flagrantly as, "A single number of the British Medical Fournal contains about 100,000 words or about $5,000,000$ in the course of a year'.

The book is a well-meant attempt to do something that badly needs doing, and the principles set out on page 7 are admirable: ' To achieve clarity you must attend to four things, you must be brief, you must choose the words that most accurately express your meaning, you must observe the rules of grammar, and you must arrange the words according to their relative importance'.

Yet the book is disappointing because it does not give medical writers the help they badly need. Anyone who tells you ' how to do it' must be very careful that he does it pretty well himself; the demonstration by the instructor is watched closely by his pupils and critics. Here the instructor does not perform well enough to give the readers confidence or to protect himself from critical scrutineers. The motes $\mathrm{Mr}$. Roberts finds in his brothers' pens seem small when larger motes are left untouched, and when there are quite a lot of beams in his own pen.

There are too many defects in both the style and the substance of the book. The style is turgid and woolly. When the author wants to say that during the last 6o years Western people have advanced further in knowledge than ever before, he writes (p. 57): 'After remaining almost static for several centuries, Western civilization has entered upon a period of ever-growing dynamism ', and when he wishes to explain that the standard of medical writing is not deteriorating, he puts it thus: "Taking these facts into consideration, it would, I think, be difficult to make out that any literary deterioration has taken place'.

Dr. Ffrangcon Roberts rightly cautions us to avoid words such as 'horribly' or 'terribly', because by showing our feelings too obviously, they weaken our argument; but he weakens his own argument by calling words which show your feelings, 'words signifying subjective impressions' and by his own use of emotionally toned words, for instance 'the sooner the ghastly remains return to the grave the better' (of serendipity, p. 147) and 'this monstrous pompous bastard' (of armamentarium, p. I8).

In many places the author gives you the feeling he is out to show you how badly you do it, rather than help you to do it well, and the large number of minor offenders that are pilloried strengthens this impression. The word 'moon-like' to describe a face receives the comment: "What kind of moon-new, half, or full' (sic, no question mark). 'Dysarthria' is criticized because the word might get confused with arthritis. $C$ To use the word electroplexy instead of electric shock is classed as " sheer pedantry, and cannot be too strongly, condemned'. Surely 'moon-like' and 'dysarthria '음 cause little confusion, and most people think of an $\frac{\bar{\sigma}}{\sigma}$ electric shock as a frightening, painful thing, whereas $\overline{\bar{c}}$ electroplexy causes no pain but produces unconscious- $\frac{\rho}{T}$ ness and amnesia. Criticizing established words gives $\mathbb{\Phi}$ no help to writers, for such words have come to stay, however faulty their origins. For example, 'hæmo- $\infty$ philia '- no term could be more absurd. A better $\vec{\circ}$ word would be hæmapexia '; 'tetralogy '-' the proper'meaning of tetralogy is a group of four discourses. $\vec{\omega}$ A better word would be tetrad'. These comments do. not help authors.

Ideally, medical writing should be so clear that there is no chance of it being misunderstood, but several passages in this book are far from this standard. On p. 126 we read: "The association of angina with throm-is bosis of the coronary arteries gave it the name coronary thrombosis. Exophthalmic goitre described two of the prominent characteristics-protrusion of the eyes and $\mathrm{N}$ enlargement of the thyroid'. On the same page we

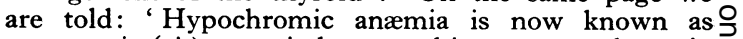
macrocytic (sic) anæmia because this expresses the main feature of the disease'. Not only is that entirely $\square$ incorrect, but it also suggests that a term denoting the size of a cell can replace one describing the depth of its colour, which it could never do because these things $\vec{\theta}$ vary independently. Lack of elementary hæmatologiogl knowledge is also shown by the passage (p. 36): "Bis. trinsic is the opposite of intrinsic and means adves titious or not essential '. Though that is one of the meanings listed by the dictionary, it is hardly the one to choose when the medical use of the adjective is commonly attached to a substance essential to life.

There is a confusing passage on p. I ro: "Here is $\frac{\mathbb{Q}}{\mathbb{Q}}$ Case X from the Third Book on Epidemics (by Hippocrates). As was to be expected from so distinguished a scholar, the translation* is accurate and literal'. 3

A similar piece of muddled writing occurs on $p$. 15, where we are told: "Apart from colloquialisms and technical terms, the fact that you are writing on a medical subject does not justify you in adorning that $\frac{}{3}$ subject with words that you would not dream of using in ordinary speech'. Presumably that means you can $\bar{\sigma}$ use the idiom of normal speech for medical articles apart from colloquialisms, and that you can keep to $\bar{\partial}$ that idiom apart from a few technical terms. It is puzzling to have exceptions of exclusion and exceptions of inclusion in one sentence; it seems like saying, 음 'Invalid diet should be much the same as ordinary $D$ food apart from Benger's Food and pickled whelks'.

An odd blunder for an experienced writer to make is: "Inverted commas enclose quotations or " quotes" N as they are technically called'. The technical sense of 'quotes' when used by printers and publishers is $N$ ' inverted commas' as in 'single quotes' or 'double స్ quotes'.

In short, this book has too many faults and gives too little help for it to be recommended to aspiring medicalo authors. *Translated by W. H. S. Jones. Who is the
distinguished scholar? Hippocrates or Jones? 